University of Wollongong

Research Online

Faculty of Social Sciences - Papers (Archive) Faculty of Arts, Social Sciences \& Humanities

2017

Crossing Rivers, Revisiting Trauma, and Contemplating the Geo: Thinking into the Anthropocenic

Justin Westgate

University of Wollongong, jsw719@uowmail.edu.au

Follow this and additional works at: https://ro.uow.edu.au/sspapers

Part of the Education Commons, and the Social and Behavioral Sciences Commons

Research Online is the open access institutional repository for the University of Wollongong. For further information contact the UOW Library: research-pubs@uow.edu.au 


\title{
Crossing Rivers, Revisiting Trauma, and Contemplating the Geo: Thinking into the Anthropocenic
}

\begin{abstract}
The irony of the Anthropocene-an idea grounded in earth sciences-is that it acts to unground some of the foundational ideas about the world. It asks us to reevaluate and rethink the human-nature binary, to inhabit a world less hospitable and malleable than we dared to believe. I explore this notion of groundlessness by returning to a personally traumatic event that literally swept me off my feet-crossing a river. I argue that the experience of such corporeal vulnerability can provide fertile ground for reorienting our own perception. Delving into such experiences may be used to provoke and expand thinking with a view to grappling with the implications of living within conditions of an Anthropocenic world.
\end{abstract}

\section{Keywords}

into, thinking, geo:, anthropocenic, contemplating, crossing, trauma, revisiting, rivers

\section{Disciplines}

Education | Social and Behavioral Sciences

\section{Publication Details}

Westgate, J. (2017). Crossing Rivers, Revisiting Trauma, and Contemplating the Geo: Thinking into the Anthropocenic. GeoHumanities, 3 (1), 233-245. 


\title{
Crossing rivers, revisiting trauma and contemplating the geo: thinking into the Anthropocenic
}

\author{
Justin Westgate \\ University of Wollongong
}

\begin{abstract}
IMMERSION
When the river took me there was little I could do. My left foot found no secure footing, only a channel of fast-moving water. I hardly had time to think. Off balance as my foundering foot was dragged away by the current, the rest of my body had no choice but to follow. "I'm gone!" I exclaimed - hoping my river-crossing buddy would hear. It was all I had time to say as the water swept me away downstream.

The river was in full flood now. The water was high and fast-flowing. It had been raining continuously for the past 24 hours, and the river's volume had continued to swell. We had made the decision to continue our journey - a circuit hike in the Kaimai-Mamaku Forest Park in the eastern part of the North Island of New Zealand. I had been in the park before, and was used to it being wet and muddy. This trip - a short three-day, two-night hike - was a chance to get away over a long weekend. While the weather conditions had started out pleasant, they'd turned during the second day to overcast and the drizzle started later that afternoon. I hadn't expected this change. I would later find out that it was the tail end of a tropical storm in the Pacific that had moved further south than expected.

New Zealand's North Island is dominated by a series of mountain ranges which form part of the 'backbone' of the country. Sitting between two tectonic plates - the Pacific and Australian - New Zealand is a land formed by the friction of these. It cuts the country almost in half, forming a series of volcanic cones - some still active - in the North Island, and the South Alpine Range forming the rocky mountainous ridge of the South Island (see Figure 1). The ranges in the north pale somewhat in comparison to the scope of the southern ranges, being largely subalpine in nature. Those in the northeastern part of the North Island mark the beginning of the country's backbone. The Coromandel Range forms the peninsular that sits to the east of the county's main northern spur. This runs down into the Kaimai Ranges, which in turn joins the Mamaku Ranges. Covered in forest, Europeans found these a rich source of high-quality timber, which was extensively logged



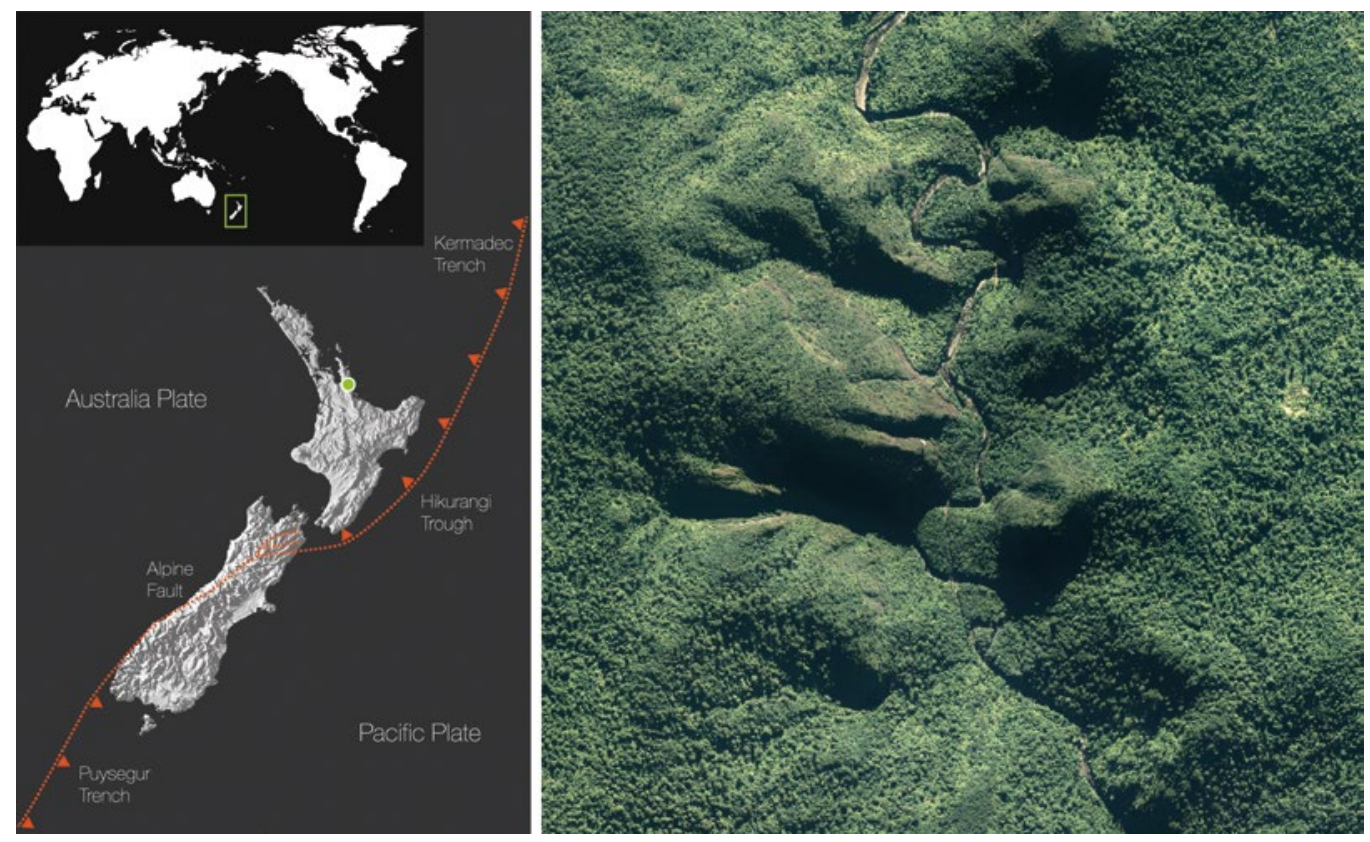

FIGURE 1 New Zealand sits across the meeting of two tectonic plates which have shaped the country's landscape. The Kaimai-Mamaku forest park is located in the northeast of the North Island. Aerial imagery shows the Waitawheta Gorge, which cuts through the volcanic strata of the Kaimai Range. Satellite imagery copyright Land Information New Zealand.

during the 1800s. Later, gold was discovered and ushered a second wave of extractive activity (Te Ara 2015). River systems were crucial to these activities. Today these North Island mountain ranges make up a network of forest parks. Important not only as areas of natural conservation, they have historical cultural significance and provide recreational amenity. Figure 2 shows the ruggedness of this sub-alpine landscape.

Indeed our exit route followed an old tramway built in the mid 1800s for both gold and timber extraction. It would return us to where our party of five had begun the journey three days earlier. Its path followed the course of the Waitawheta River, a waterway beginning in the ranges and flowing eastwards to the coast, crossing it many times. The first of these was only shin-high, but at each subsequent crossing the water level was higher. At the sixth crossing the group linked arms and forded water now up to our chests. This height was becoming concerning but our map showed only a few crossings before we would leave it. We'd come this far, and backtracking had increasingly become less of an option.

After our chest-level crossing the route continued along the side of the river for half an hour before it descended for another. But here, instead of finding a high but relatively slow-moving river, now the water was fast-flowing. Rocks and boulders curdled the water making the surface broken and white. Here the geology of the terrain had changed. The sides of the valley steepened; the width of the river had begun to narrow directing the water into a concentrated channel, increasing its velocity. 


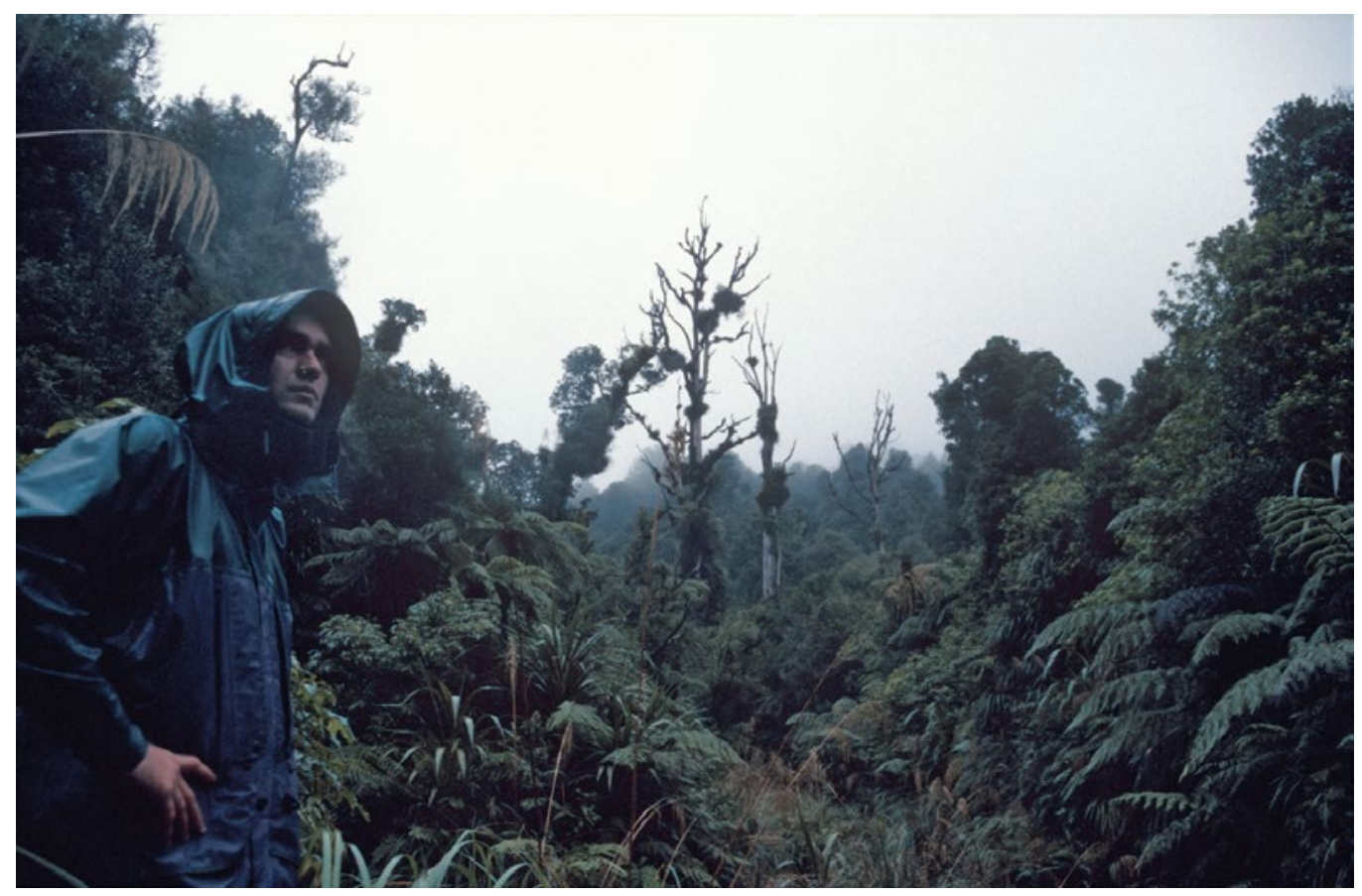

FIGURE 2 A member of the group poses for a photo in the rain early on in the day. Photo by the author.

Assessing the situation we decided it was not safe to cross; we'd need to find an alternative path. Scouting downstream we discovered that the river widened and eased a little before moving around a bend. It was still fast moving but appeared safer.

A colleague and myself volunteered to test the crossing. I had experience; my friend - an avid weight lifter - had bulk. While the rest of the group watched from the bank, we edged our way into the rapids. My friend was upstream, I was down; we interlocked our arms between our backs and our packs, providing extra stability.

The riverbed was rocky, and the turbulence of the fast-flowing water made seeing beneath it almost impossible. Our feet were forced to search for footholds amongst the river stones, which afford little traction. But the water, while swift, was not so deep - only up to our thighs. We made slow but steady progress, one step at a time; balancing, positioning, taking another step. We were close to half way across, and I was beginning to feel confident that we would make the other side. But it was here that we encountered the unexpected.

While the widening of the river had allowed the water to spread laterally, a central trench remained in the riverbed that still directed a good portion of water. This was not visible from the surface. And it was this channel of fast-moving water that my left foot found as I took another step forward. Expecting to find some rock beneath, instead I found nothing. The drop was not that great - perhaps only a foot - but enough to take me by surprise. And the force of the flowing water was considerable. 

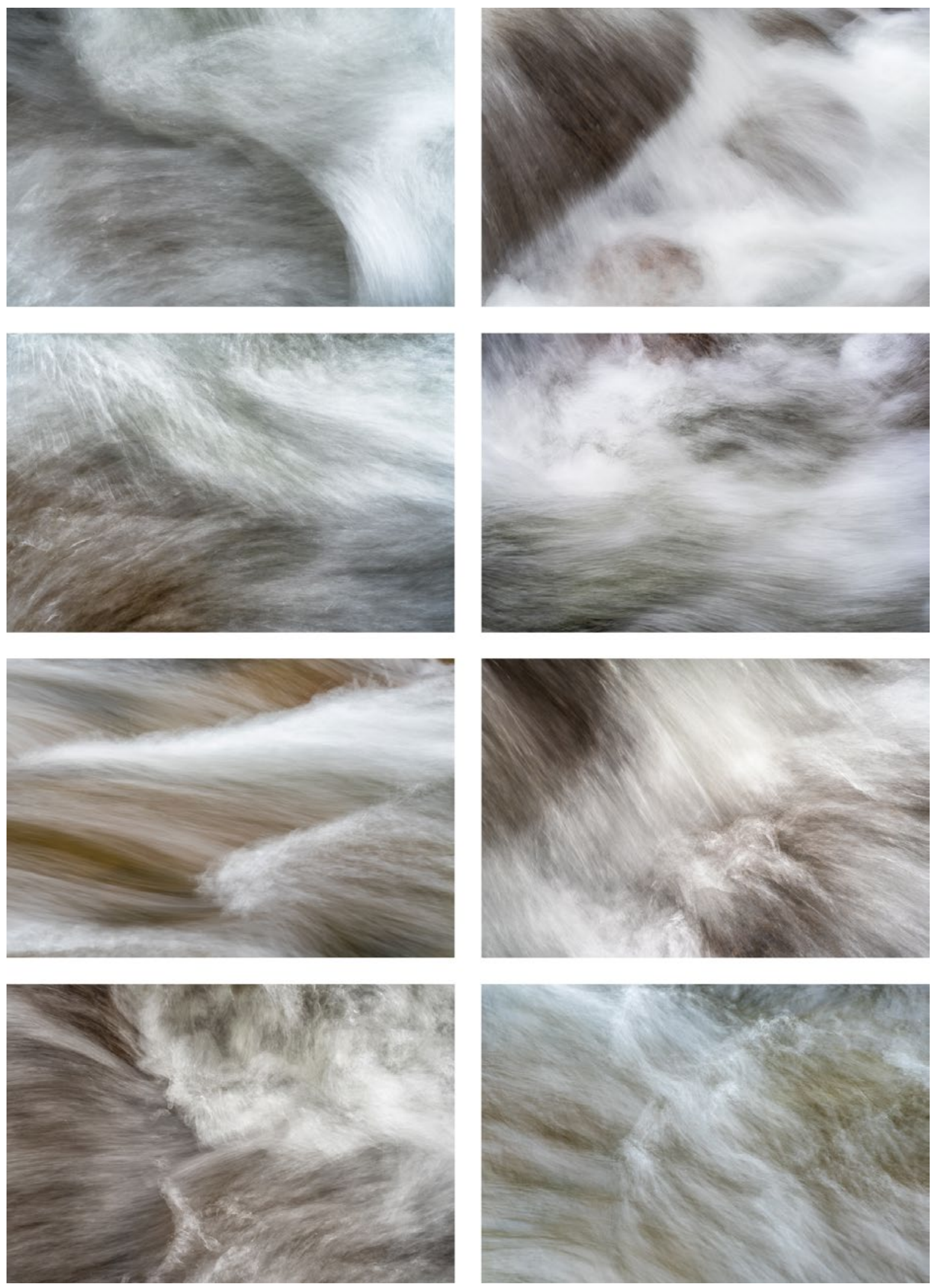
I barely remember the events of that moment. I remember stepping. I remember finding nothing. I remember feeling the force of the water sweep my foot sideways and me off balance. I remember uttering the words "I'm gone" quite matter-of-factly. I don't remember how I managed to land on my back - perhaps it was because my feet went first - but it was lucky that I did.

What I do remember is my mind racing. As the water took me I felt a surge of panic like I had never experienced. I was riding atop a churning, racing flow of water. It was also cold. As cliché as it sounds, images of my life raced through my mind; time seemed to slow down.

My instinct was to try to stand but my feet found no traction. The force of the current was too strong. Then: 'thwack!' The shin of my right leg hit a boulder and glanced off. My gaiters - canvas lower-leg coverings - gave me some protection, but it hurt. I was moving too fast; the middle of the river was too deep and fast flowing. The pack on my back gave me buoyancy - and protection - but I was battling to keep control of my orientation. Better, I thought, to try and navigate to the side where it would be shallower - hopefully. I knew that further downstream the river hit a wall of sheer rock - the beginning of a gorge - then made a 90-degree turn to the right and both sides became sheer rock walls. At the moment, though, there was still a flat riverbank and bush - a possibility of escape.

Using my feet to fend off boulders, I used my arms to 'paddle' closer to the bank. Whether it was this or a skew of the current I found myself edging closer to the riverbank. Thrusting my foot down it made contact and held. My other foot caught and, stopped, I grabbed a boulder to my right and pulled myself into a standing position. I stood, heart pounding, mind racing, shivering, and looked back up the river. The rest of the group was out of sight upstream, and I saw no sight of my river-crossing companion. I had no sense of how long I'd been in the water, or how far downstream I had come - it may have only been thirty seconds, maybe a minute or more, but it seemed like an eternity.

In a moment things can change. When the ground you know is swept from underneath your feet it can change how you understand the nature of the world.

\section{SURFACING}

I focus on this event not only because it was a significant one personally but because it was something that my thoughts came back to as I began to interrogate threads of Anthropocenic thought. Here I move to trace thinking about the Anthropocene, examining its implications through the geologic and into cultural thought. My aim in doing so is to consider how trauma may be used as a frame with which to think through the Anthropocenic.

While an 'age of humans' has been mooted for almost a century (Steffen et al 2011; Hamilton and Grinevald 2015), a more recent provocation by Crutzen and Stoermer (2000) has rekindled the idea. This argues that the modern era has seen increasing planetary impact by humans, enough to move us out of the assumed current stable geological epoch - the Holocene - into a new unsettled one - the Anthropocene. For a decade the idea remained largely within the earth sciences given its material and temporal associations. More recently, however, the idea has been taken up and interrogated by other disciplines - indeed the constituents of the Anthropocene are argued to have specific cultural and political entanglements (see: Johnson et al 2014; Haraway 2015; Moore 2016). Beyond its material implications the Anthropocene points to a profound shift in understanding 
the human-nature duality, the consequences of which are as far-reaching as Darwin's proposal of evolutionary theory that dared to suggest that humans were no longer divine creatures (Steffen et al. 2011). As Castree (2014) underlines, the impacts of this are:

“... so profound as to require searching self-examination about the habits of social thought and action that have given rise to them. The changes, if taken seriously, oblige societies to 'regraph the geo' imaginatively and practically."

-Castree (2014, p464)

The challenges of the Anthropocene are therefore many, but the immediate one is with sensing and comprehending it (Cook and Balayannis 2015; Davis and Turpin 2015). The vastly distributed scale at which it operates is abstracted both physically and temporally (Morton 2012) - and ultimately it is removed from our experience of daily life.

To inhabit this new era, this 'new normal'; this catastrophe in progress; this ontological overturning, asks us to radically shift our perception of the world and our place in it (see for example McKibben 2010; Wilke 2013; Johnson and Morehouse 2014; Head 2015). The question I grapple with is how we might do this. We can, for instance, employ thought experiments "to stretch and... invert our thinking in order to imagine alternative possibilities." (Head 2015,314); or use narratives “...in ways that weaken rather than reinforce modern ontologies..." (Davidson 2015, 302). Here I use narrative as a creative way to explore geographical ideas (see Daniels and Lorimer 2012), doing this through personal and embodied experience - and through trauma (see Scranton 2016).

In doing so I align myself with a critical framing of the Anthropocene - one that avoids a reading of human triumphalism, but rather poses crucial questions about the repositioning of the human a decentering (Anderson 2013; Yusoff 2013; Kelly 2014). As with Darwin's proposal this triggers something of an existential crisis, and by using my own experience of a traumatic event I aim to explore the vulnerability that this exposes as a kind of rupturing of an accepted experience of the world.

The body, embodiment and affect are topics of recent investigation within geographical thinking, with a focus on the body-in-action providing a primary mechanism for the creation of meaning and signification, and disclosure of the world. This work, however, has tended to focus on the 'positive' or active capacities of bodies, paying little attention to the body's incapacity, such as through vulnerability (Harrison 2008). Subsequently this thread has been taken up and I align myself with this work that seeks to explore bodily vulnerability and it relationship to planetary and geologic processes (see for instance Clark 2007, Clark 2010). Here vulnerability emerges as highly relevant in considering living on unstable ground. The Anthropocene proposes this at the species level, but at the individual level I'm interested in the challenge this presents. Displacing one's own sense of importance or entitlement is not easy, though it may be necessary to adopt this orientation if we are to live in a world that is not as hospitable or malleable as we had once believed. How might we then inhabit this new world?

To be sure, we can look to research that considers the phenomenon of traumatic experiences on the individual. Psychology is interested in how we respond to such events in our lives - traumatic events - and particularly how we form resilience to cope with these, as well as how they can contribute to personal growth (see Meichenbaum et al 2006). Near-death studies is a discrete branch that investigates experiences reported by people who have come close to dying - both the phenomenon of the experience itself as well as personal impacts after the event (Worth Bailey and Yates 1996; Engmann 
2014). Yet, I want here, to remain cognisant of the geological, as a ground on which the Anthropocenic is founded. Indeed modern psychology owes a debt to geology - the geological notion of stratigraphic layering influenced Freud's ideas layers of human consciousness.

Moments of trauma can be powerful. They may fracture the seemingly stable surface revealing the substructure beneath. In the physical world we can think of freak natural events that act to reveal more about a landscape: an extreme low tide that reveals hidden archeological remains; a storm that washes away topsoil revealing artifacts concealed by layers of sediment.

Natural disasters affect human lives on more than the individual level. Impacts are also more than material; they influence our very ideas about the world. The immense earthquake that struck Lisbon in 1755 , causing catastrophic tsunamis and a subsequent razing of the city is a case in point. It is the largest recorded natural disaster in Europe, considered the first modern disaster (Dynes 2003). The human loss of life was large, certainly for the time - an estimated 90,000 lives (more than one-third of the city's population). But more importantly it triggered a raft of questioning and cultural examination in an effort to understand and make sense of the event. It is no coincidence that phrases such as 'to shake (or rock) the foundations,' 'groundbreaking' and 'earth-shattering' are based on geologic imagery - the impacts of the Lisbon quake linger within language and our cultural psyche (Neiman 2002). The resulting project of enquiry was perhaps more important than the event itself as it redirected the flow of cultural thought - its influence we still feel today. It put into doubt Descartes' argument for a 'harmonious and well-ordered universe', and - as Voltaire pointed out at the time - the existence of a benevolent deity. It instigated a shift for Kant's thinking towards an empirical focus, importantly laying the foundations for a 'scientific geography'. (Hamacher 1999; Larsen 2006).

This is a thread that Clark (2011) looks to in grappling with our contemporary relationship with the earth. Yet, where Anthropocenic ideas would suggest that human activity has grown commensurate with forces of nature, Clark is not completely swayed. To him the earth is largely indifferent to us; its planetary fluctuations are an inherent part of its nature. This is not to deny the impacts that human activity can have, but humans do not dominate the Earth as some would suggest. We are no way 'in control' - either individually or collectively. Our challenge is coming to terms with our relationship to an inherently dynamic world; comprehending the different rhythms of natural systems. This is an alien dynamism, different from our own experience of the world. But it can be within moments of tumult - events that breach the imagined divide between the human and the natural world - that expands our understanding:

A major upheaval of the earth, survivors tell us, not only takes the ground out from beneath your feet, but unravels the very fabric that holds things together and allows us to make sense of the world. (Clark 2011, xvi)

This 'fabric that holds things together' is of course our set of ideas about what the world is and how this operates. And I want to briefly consider how one 'survivor' makes use of a traumatic experience through the work of Val Plumwood. This was not an encounter with the volatile earth forces but, nonetheless, an encounter with 'nature' that challenged Plumwood's own foundational perceptions of the world.

Plumwood was an Australian environmental philosopher and activist, active from the 60s until her death in 2008. Her work takes a feminist stance, exploring human separation from nature what she terms 'hyperseparation' - and argues the need to reintegrate this division. Her later work draws on an experience of being attacked and almost killed by a crocodile whilst on a canoeing 
trip in Kakadu National Park in the northern part of Australia. It was an event that caused her to think deeply about her own perception of the world, coming to the conclusion that this outlook had been limited by an inherent anthropocentricsm. The traumatic confrontation with this predatory animal forced her to see herself through its indifferent, animal eyes. It provoked her to consider herself - and humans - as mere pieces of meat; as simply a source of food for such predators. This realisation instigated a fracturing of the driving narrative of human dominance and importance (Plumwood 2012).

And, while I have an affinity with Plumwood's arguments for more an animistic outlook, my interest here is with the process - the experience - that stimulated these insights. For Plumwood, her near-death experience was not something to be bemoaned or repressed - in fact quite the opposite - she used it as a rich event through which she was able to interrogate not only herself but her thinking about the world:

Some events can completely change your life and your work, although sometimes the extent of this change is not evident until much later. They can lead you to see the world in a completely different way, and you can never again see it as you did before. You have been to the limit, and seen the stars change their course. That extreme heightening of consciousness evoked at the point of death is, as many testify, of a most revelatory and life-changing kind - for those who, against all odds, are given a reprieve and survive. The extraordinary visions and insights that appear in those last seconds can be hard to reconcile with our normal view of the world. In the vivid intensity of those last moments, when great, toothed jaws descend upon you, it can HIT YOU LIKE A THUNDERCLAP that you were completely wrong about it all - not only about what your own personal life meant, but about what life and death themselves actually mean.

-Plumwood (2012, 11; original emphasis)

Plumwood writes eloquently about the ramifications of her experience, connecting the personal with the philosophical, developing a narrative that we, as readers - and as humans - readily connect with. And here I want to make a point about the ways in which we might consider writing about - more broadly expressing ideas about - events which threaten human life. We can write about these events from a distance, making sense of them, using them to extend our thinking about the world - what we might call 'armchair investigation' as Clark (2011) does in the case of Kant's interrogation of the Lisbon earthquake. But we can also use actual experience of such events to provide different kinds of insights, as Plumwood manages to do. And, as separated as they are by time, culture, place, philosophical outlook, and indeed their kinds of experience, I find it interesting that both grapple with this notion of indifference of Nature towards us. They do this in quite different ways: Kant in trying to understand the volatile forces of the earth seeks to remove meaning - seeking to silence nature in the kinds engagements we have with it - applying a classical rationalism; Plumwood, in contrast, provides an opening for locating meaning. But this is not where we might ascribe intention or meaning to Nature, rather it is about us - humans - being more attentive to the nature of Nature; attempting to better understand our relationship with it. Plumwood, in the same vein as Clark, comes to the conclusion that Nature is indeed indifferent to us. It does not really care; if it does it is because we are food, and Nature is always hungry. This is a challenge to our sense of being human. Experiencing our corporeal vulnerability can reveal to us that we are not as removed from or in control of natural forces as we would like to believe. The invitation that Plumwood and Clark extend is to consider this, and to better understand Nature on its own terms. 


\section{EXTRACTION}

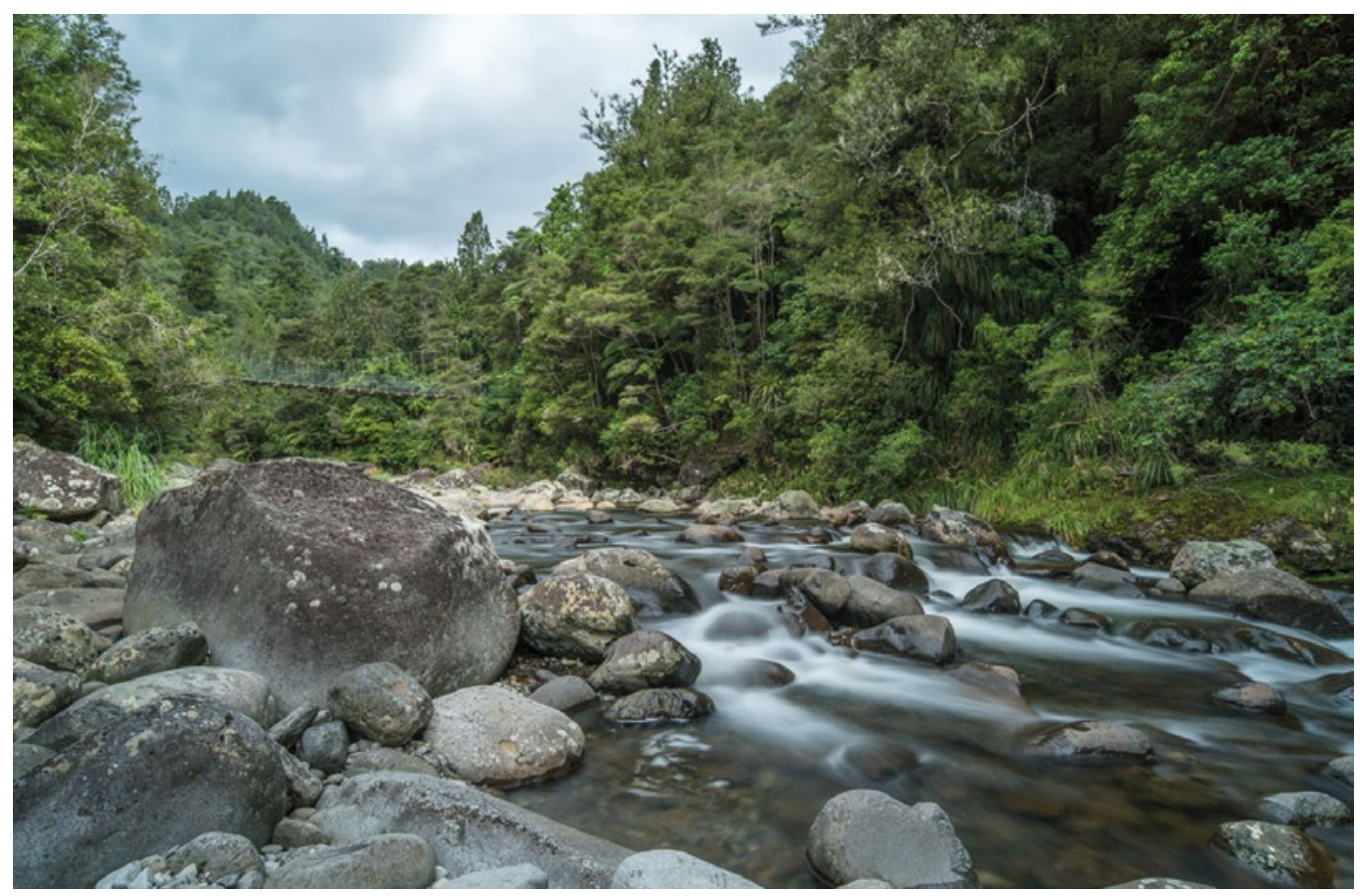

FIGURE 3 Members of the hiking group settle in to spend a night in the bush beneath a rock overhang. Photo by the author.

My extraction from the river was not the end of my ordeal at the time. After locating my river-crossing buddy clutching a boulder mid-river, assisting him and regrouping with our party we found ourselves on the wrong side of the river. A day of navigating through rugged and uncharted bush failed to lead us out before dark set in. Still in the bush and off the track we w ere forced to spend a night out in the open, fortunately finding refuge under a rocky overhang that provided shelter from the continuing rain (see Figure 3). We found our exit, finally, the following day, returning back to the car park at dusk only to find a search and rescue team preparing to enter. Yet it was returning to the city - 'home' - that was the culmination of the experience. What had once seemed everyday, familiar, normal, now appeared decidedly unreal. The ordeal had effectively ruptured our shared perception of 'reality'. For myself it took many weeks before a pervading sense of surrealness eventually dissipated.

My aim, therefore, in thinking through personal trauma has been to find a vehicle through which I might explore a profound shift in my own accepted experience of the world; to aid me in inhabiting the ontological trauma of the Anthropocenic.

In returning to this event it became evident that this would require revisiting the location; I had not been back in some 15 years since it occurred. Thus I undertook to spend time in the area, camping by the side of the river and retracing the events that took place. I revisited images and notes I had 


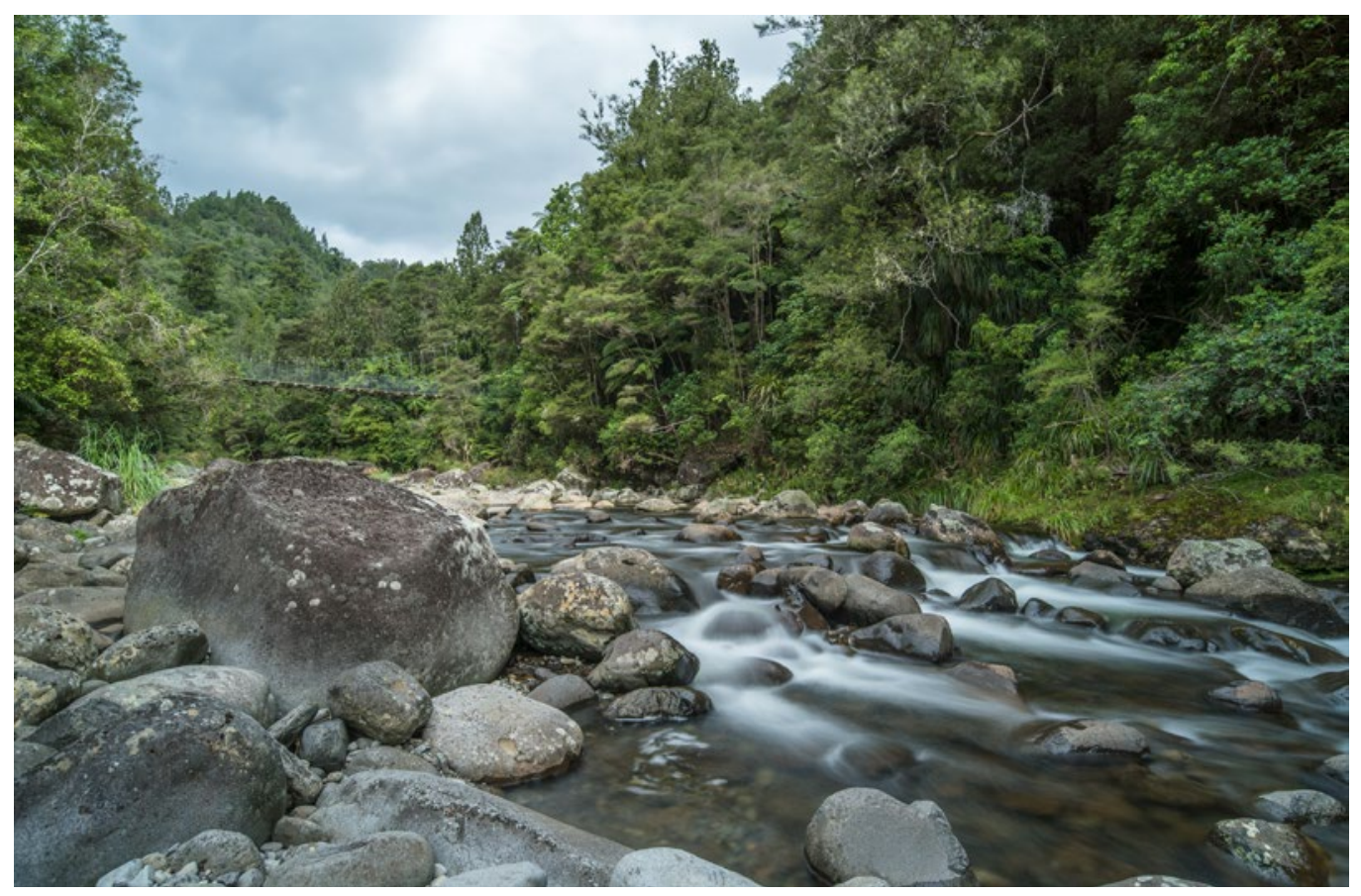

FIGURE 4 Location of the crossing event. A recently installed suspension bridge hangs in the background. Photo by the author.

taken at the time, and undertook to record my reflections through both writing and photography (see Figures 4, 5). What is presented here is a truncated version of a larger chapter detailing this. Returning to the site, however, did not reveal the kinds of things I expected. It gives me a better sense of the geography of the area, as well as geology. And, having seen the course of the river from further downstream it leaves me with a sense of how fortuitous we were to escape being flushed into the gorge itself, which most certainly would have been fatal.

This, surprisingly, is the most unsettling thought from my revisit; there is no anxiety, no re-lived sense of terror. Of course my return is timed to be under more hospitable conditions which lets me see a different character of the river. This gives me the opportunity to contemplate both the event and this river-thing. For all its pleasantness I'm able to read the signs of its fluctuating nature: water-scoured rock faces, pools of deep water, eroded river banks, distressed vegetation patterns - evidence of different conditions.

Returning to the river expands my own limited sense of the geo - I've not studied geo sciences or physical geography. But at the crossing point, searching for familiar markers - particularly the boulder that saved my friend - I contemplate the dynamism at work. I begin to see the river not as movement of water but rather a flow of rock and other matter. This disrupts my narrow sense of human-scale time, and expands it into the geologic. What would it be like to stand in place and watch this flow over 10,000 or more years? Stones and boulders would then flow like liquid. It helps me perceive rock and strata as inherently more dynamic and 'vital.'

I ask myself further what this river is to me. It seems wrong to hold a grudge against a river, which, 


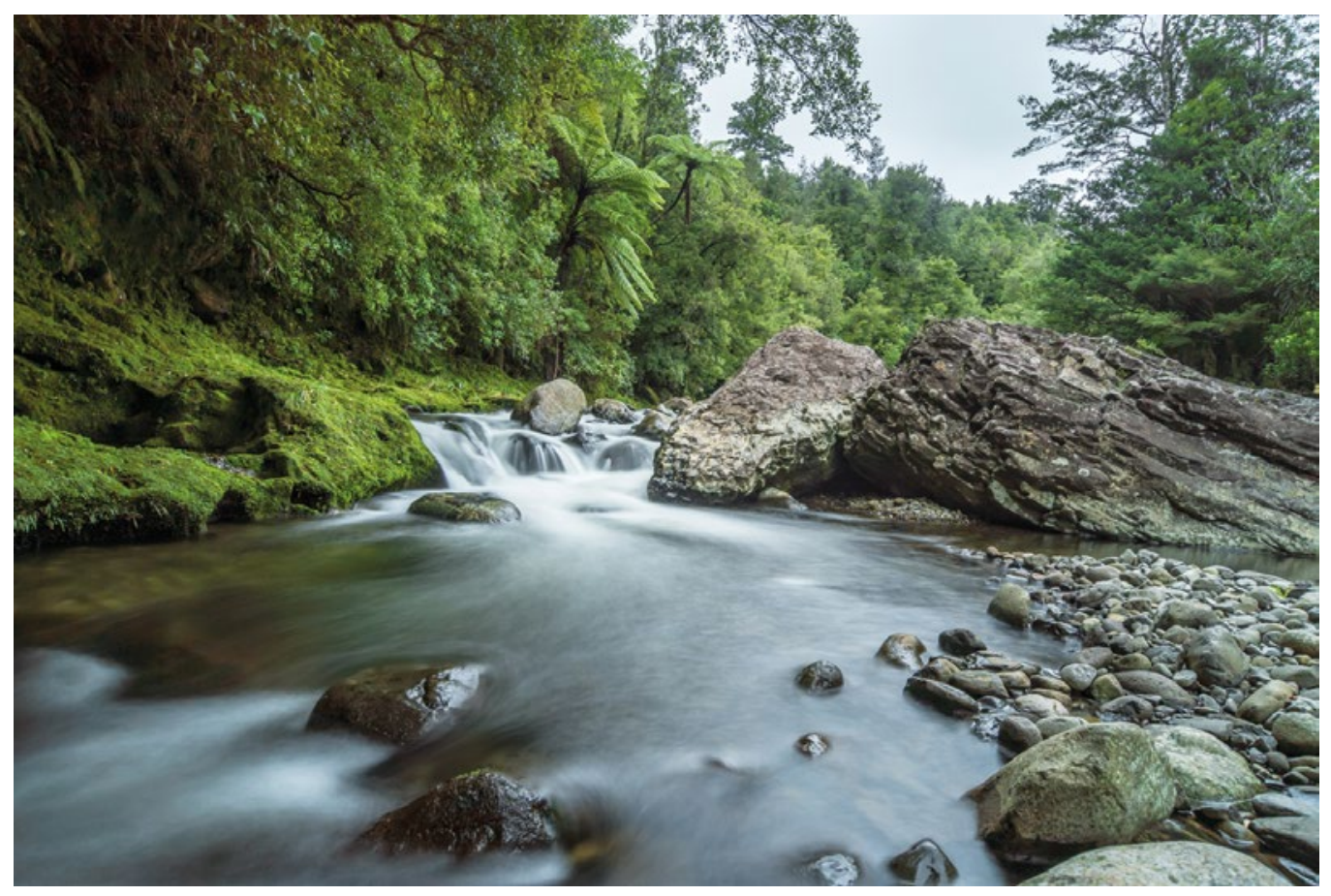

FIGURE 5 Under more pleasant conditions the river shows its scenic qualities. Photo by the author.

is ironic because it is possible to be fond of one. A river is just being a river, it is not trying to impress you, or upset you, or take your life. We humans understandably want to anthropomorphosize things in the world. There is a challenge in understanding the nature of things in the world on their own terms - however attainable that may be. And, here, returning to this point of fracture opens up thinking that is more contemplative; poetic.

For me this essay is a first step into uncertain ground; with the Anthropocenic. As it was for Plumwood thinking through personal trauma and attending to felt vulnerability (Harrison 2008) suggests a way of gaining novel insights of one's ontology; expanding one's sense of 'reality' and conceiving of a world quite different to the one which we believe we live in. This is a world in which "[w]e're going to need new ideas... need new myths and new stories, a new conceptual understanding of reality..." (Scranton 2016, 19). The Anthropocene confronts us with conceptual and existential challenges that have no logical or empirical answers, and Scranton suggests that we need to 'learn how to die,' not just individually but as a civilization.

In my case, this experiment in returning to an event of trauma and vulnerability helps me contemplate what it might be like to inhabit this space. It aids me in 'slowing down,' cutting through normative perception, helping me consider the implications for myself in a world constituted differently. Becoming more at ease existing on unstable ground opens up thinking about how I might find my own pathway forwards across such terrain. My own navigation looks to tools that provide more flexible and responsive mechanisms; methods more creative, experimental; that are able to both unpick and restitch this 'fabric that holds things together.' 


\section{REFERENCES}

Anderson, K. 2013. Mind over matter? On decentring the human in Human Geography. Cultural Geographies 21(1): 3-18.

Berzoff, J. 2008. Freud's psychoanalytic concepts. In Inside out and outside in: Psychodynamic clinical theory and psychopathology in contemporary multicultural contexts, ed. J. Berzoff, 17-47. Blue Ridge Summit, PA: Rowman \& Littlefield Publishers.

Castree, N. 2014. The Anthropocene and Geography III: Future Directions. Geography Compass 8/7: 464-476.

Clark, N. 2007. Living through the tsunami: Vulnerability and generosity on a volatile earth. Geoforum 38: 1127-1139.

Clark, N. 2010. Volatile worlds, vulnerable bodies: Confronting abrupt climate change. Theory, Culture \& Society 27(23): $31-53$.

Clark, N. 2011. Inhuman Nature: Sociable Life on a Dynamic Planet. London: SAGE Publications.

Cook, B. and A. Balayannis. 2015. Co-Producing (a Fearful) Anthropocene. Geographical Research 53(3).

Daniels, S. and H. Lorimer. 2012. Until the end of days: narrating landscape and environment. Cultural Geographies 19(1): 3-9.

Davidson, A. 2015. Beyond the Mirrored Horizon: Modern Ontology and Amodern Possibilities in the Anthropocene. Geographical Research 53(3): 298-305.

Davis, H. and E. Turpin. 2015. Art in the Anthropocene: Encounters Among Aesthetics, Politics, Environments and Epistemologies. Open Humanities Press.

Dynes, R. 2003. The Lisbon Earthquake in 1755: The First Modern Disaster. Newark, DE: Disaster Research Center, The University of Delaware. http://dspace.udel.edu/bitstream/handle/19716/294/PP\%20333.pdf (last accessed 6 January 2016)

Engmann, B. 2014. Near-Death Experiences: Heavenly Insight or Human Illusion? Cham: Springer International Publishing

Hamacher, W. 1999. Premises: Essays on Philosophy and Literature from Kant to Celan. Palo Alto, CA: Stanford University Press.

Haraway, D. 2015. Anthropocene, Capitalocene, Plantationocene, Chthulucene: Making Kin. Environmental Humanities 6: $159-165$.

Harrison, P. 2008. Corporeal Remains: Vulnerability, Proximity, and Living on after the End of the World. Environment and Planning A 40(2): 423-445.

Head, L. 2015. The Anthropocenans. Geographical Research 53(3): 313-320.

Johnson, E., Morehouse, H., Dalby, S., Lehman, J., Nelson, S. and Rowan, R., Wakefield, S. and K. Yusoff. 2014: After the Anthropocene: politics and geographic inquiry for a new epoch. Progress in Human Geography 38(3): 439-456.

Kelly, E. 2014. Anthropocene Hospitality: belonging in/to a changing climate. Scan Magazine 11(1). http://scan.net.au/ scn/journal/vol11number1/Elaine-Kelly.html (last accessed 5 July 2016).

Larsen, S. 2006. The Lisbon earthquake and the scientific turn in Kant's philosophy. European Review 14: 359-367.

Margolin, U. 1994. Russian Formalism. In The Johns Hopkins Guide to Literary Theory and Criticism, eds, Groden, M., M. Kreiswirth and I. Szeman. Baltimore, MD: The Johns Hopkins University Press.

Meichenbaum, D., L. Calhoun and R. Tedeschi. 2006. Handbook of post-traumatic growth: Research and practice. Mahwah, NJ: Lawrence Erlbaum: 355-368.

McKibben, B. 2010. Eaarth. New York, NY: Henry Holt and Company.

Moore, J. 2016. Capitalism in the Web of Life: Ecology and the Accumulation of Capital. Brooklyn, NY: Verso Books.

Morton, T. 2013. Hyperobjects: Philosophy and Ecology after the End of the World. Minneapolis, MN: University of Minnesota Press.

Neiman, S. 2002. Evil in Modern Thought: An Alternative History of Philosophy. Princeton, NJ: Princeton University Press.

Plumwood, V. 2012. The Eye of the Crocodile, ed, L. Shannon. Canberra: Australian National University E Press.

Scranton, R. 2016. Learning to Die in the Anthropocene: Reflections on the End of a Civilization. San Francisco, CA: City Lights Publishers.

Steffen, W., Grinevald, J., Crutzen, P. and J. McNeill. 2011. The Anthropocene: conceptual and historical perspectives. Philosophical Transactions of the Royal Society A 369: 842-867.

Te Ara. 2015. The Encyclopedia of New Zealand: Landscapes. Ministry for Culture and Heritage. http://www.teara.govt. nz (last accessed 22 Oct 2015) 
Wilke, S. 2013. Anthropocenic Poetics: Ethics and Aesthetics in a New Geological Age. In Anthropocene: Envisioning the Future of the Age of Humans, ed. H. Trischler, 67-74. Munich: Rachel Carson Centre.

Worth Bailey, L and J. Yates. 1996. The Near-Death Experience: A Reader. New York, NY: Routledge.

Yusoff, K. 2013. Geologic life: prehistory, climate, futures in the Anthropocene. Environment and Planning D: Society and Space 31: 779-795. 